\title{
¿Es posible el empoderamiento en tiempos de crisis? Repensando el desarrollo humano en el nuevo siglo
}

\author{
Is Empowerment Feasible in Times of Crisis? Rethinking \\ Human Development in the New Century
}

Recibido: octubre 4 de 2012 | Revisado: diciembre 10 de 2012 | Aceptado: diciembre 12 de 2012

\author{
ALIPIO SÁNCHEZ VIDAL * \\ Universidad de Barcelona, España
}

\begin{abstract}
RES U MEN
Se hace una reflexión abierta sobre la viabilidad del empoderamiento psicosocial en la actualidad. Tras examinar algunos efectos sociopsicológicos de la actual crisis económica, se proponen las cuestiones básicas (significado teórico-ideológico, viabilidad práctica, nivel operativo, carácter subjetivo u objetivo) implicadas en el empoderamiento y se describen las dificultades del empoderamiento microsocial frente a las tendencias (concentración, opacidad, lejanía, incomprensibilidad) del poder macrosocial en el mundo postindustrial. Se apuntan algunos retos prácticos del tema para la psicología comunitaria poniendo de relieve la limitación de sus medios (explicativosideológicos, técnicos, personales-morales, institucionales) en relación con los ambiciosos fines empoderadores y describiendo, finalmente, los tres componentes (subjetivo-concienciador, interactivo-organizador, acción social) del proceso empoderador y las limitaciones (y posibilidades) de la acción psicosocial al respecto.

Palabras clave autor

Empoderamiento, psicología comunitaria, crisis económica y social, poder macrosocial.

Palabras clave descriptores

Medios psicosociales, componentes del empoderamiento, España
\end{abstract}

\footnotetext{
A B S T R A C T

A reflection is made on the feasibility of psychosocial empowerment today. After describing the socio-psychological effects of the current economic crisis, a proposal of the main questions implied in empowerment (ideological-theoretical meaning, practical feasibility, operational level, subjectiveobjective character) is made, and difficulties of microsocial empowerment examined in the face of its operational divergences with macrosocial power (concentrated, opaque, distant, and incomprehensible) in postindustrial societies. Some challenges for community psychology are then pointed out reviewing the limitations of its -explanatory-ideological, technical, personal-moral, institutional- means in relation to the ambitious ends of empowerment, showing, finally, the three core components of the empowering process (subjective awareness, interaction-organization, social action) and the limitations (and possibilities) of psychosocial action regarding them. Key words author

Empowerment, community psychology, economic and social crisis, macrosocial power.

Key words plus

Psycosocial Means, Components of Empowerment, Spain.
} 


\section{Crisis económica y secuelas sociopsicológicas}

La crisis económica del mundo rico y sus amplias secuelas individuales y sociales conforman un escenario poco propicio a filosofías y prácticas psicosociales desarrollistas, basadas en la asunción de un poder y un potencial de desarrollo humano que hoy, en el nuevo y agónico escenario, parecen más quiméricas e inalcanzables que nunca. Entre las causas que precipitaron la crisis podemos destacar: primero, la rendición de la política a la economía con un trasfondo de incesante polarización económica del poder y de ruptura del tenso equilibrio que mantenían el principio liberal (que rige el mercado) y el principio democrático que garantiza el poder de la gente (Vallés, 2010). Segundo, la entrega del poder que los ciudadanos habíamos depositado en los políticos para gestionar nuestros problemas y aspiraciones a fuerzas y grupos anónimos, lejanos y aparentemente todopoderosos (los mercados) que eluden el control democrático. Tercero, la renuncia de las izquierdas a sus ideales de progreso y justicia social, a cambio de un bienestar materialista basado en un consumo sin freno y alimentado por una explosiva multiplicación del capital financiero. Cuarto, la asunción por esas fuerzas progresistas de programas neoliberales que facilitan, a través de la desregulación, el dominio de ciertos grupos económicos y financieros. Entre los devastadores efectos sociales del reventón de las diversas burbujas (financieras, inmobiliarias, energética, de las "puntocom", deudas pública y privada, etc.) podemos destacar tres:

1) El cuestionamiento de la autonomía de la política respecto de la economía y, al final, de la propia viabilidad de la democracia. Parece evidente que sin medios económicos (incluidos los financieros) no hay democracia real; para el pobre (individuo, comunidad o país) la democracia es un auténtico "lujo"; pero, incluso, si siendo económicamente rico debe dinero (o gasta más de lo que tiene o recauda), pierde la autonomía para decidir su destino. Cabe entonces preguntarse con Vallés (2010), y en contra de la supuesta y benéfica hermandad entre capitalismo y democracia, icuánto mercado puede tolerar la democracia?
2) El debilitamiento de la base relacional de la democracia: el vínculo entre ciudadanos y políticos y la confianza mutua que lo sostiene. No solo han malbaratado el poder que los ciudadanos les cedieron para organizar la sociedad en beneficio de todos entregándolo a las élites financieras, sino que, además, han traicionado -en el caso de las socialdemocracias- los ideales sociales que representaban, rindiéndose a una mística (atolondradamente compartida por el grueso de la sociedad) del dinero fácil y de un crecimiento artificial y desbocado financiado por una gigantesca masa monetaria cuya expansión descontrolada fue facilitada por la desregulación neoliberal de fines del siglo pasado.

3) El empobrecimiento y "desempoderamiento" masivo, empujando a las clases medias hacia la marginación y adentrando en ella a las minorías que ya estaban en sus bordes. Se ha extendido una sensación de impotencia y desánimo paralizador a causa tanto de los efectos directos de la crisis como de la incoherencia de las reacciones de unos gobiernos (que se han mostrado fuertes con los débiles y débiles con los fuertes), cuya intención última no parece otra que desmontar los sistemas de protección social, quebrar los equilibrios en las relaciones socioeconómicas establecidos en la posguerra mundial y cargar así los costes de la crisis sobre las espaldas de las clases medias y los más débiles, exonerando a aquellos que más contribuyeron a precipitarla. Aunque eso está generando dosis adicionales de indignación y percepción de injusticia, estos sentimientos no bastan, a lo que se ve, para rasgar el manto de desconcierto y temor que atenaza el ánimo colectivo.

\section{¿Es aún vigente y viable el empoderamiento?}

En la medida en que el devenir social nutre la teoría y la práctica psicosocial, la situación dibujada deberá afectar profundamente la elaboración teórica y la acción en el campo comunitario, proyectando serias dudas sobre la vigencia ideológica y la viabilidad práctica del empoderamiento en el mundo actual. En efecto, la idea de empoderamiento surge en Estados Unidos en un momento de euforia y exaltación 
narcisista del individuo (los años "del yo": Lasch, 1999; Watson, 2002) en una sociedad que, aunque inmersa en la crisis energética desencadenada en 1973, solo adquiere conciencia plena de ella con los recortes sociales que -junto al expansionismo monetarista neoliberal- inicia Ronald Reagan en los 80. Aunque la idea de empowerment había sido ya usada en ciertas áreas (Solomon, 1976; Berger \& Neuhaus, 1977), es propuesta en un campo comunitario (Laue \& Cormick, 1978; Rappaport, 1981) que "toma" conciencia tanto del cuasi-monopolio explicativo del sentimiento de comunidad (comprensible por la erosión de la comunidad en los países industrializados) como de la insuficiencia de ideas esencialmente individuales (autoestima, competencia, locus de control, etc.), para representar el potencial motivador y movilizador de la acción humana colectiva. Es, en consecuencia, explicable que el término empowerment hiciera fortuna tanto en el campo comunitario como en otras áreas que encuentran en él una plataforma conceptual asociada al poder, a la vez que una bandera de enganche retórica para la acción social y política de base que hace explícita la dimensión política del desarrollo humano ausente en conceptos más formalistas o ambiguos, como "derechos" o "capacidades".

Partiendo del supuesto de que los conceptos y teorías están de un modo u otro vinculados a una realidad de la que "emanan" y a la que buscan comprender o explicar, la pregunta es, entonces, obvia: iserán la idea y la práctica del empoderamiento, surgidas en momentos de optimismo y posibilidades "ilimitadas", otra víctima de la crisis y del pesimismo y recordatorio de los límites humanos que la acompañan? O bien, y por el contrario, ipodría ser que la clarificación de la conciencia del poder colectivo no ejercido y de las posibilidades de actuación social abierta por el choque crítico y sus secuelas sociopsicológicas propiciara un cambio social y cultural que incluyera la forja de un nuevo modelo de desarrollo humano menos materialista y más equilibrado en cuanto a las cualidades humanas promovidas y a los medios y métodos con que esas cualidades son promovidas? Estas preguntas, obligadas para el campo comunitario, guían la presente reflexión que tiene su origen en la IV Conferencia
Internacional de Psicología Comunitaria (Barcelona, junio de 2012). Dada la complejidad temática, la heterogeneidad subjetiva y la variedad contextual implicada en tales cuestiones y el primitivo estado de elaboración del tema del empoderamiento en psicología, mi pretensión es doble, a la par que modesta: 1) lanzar las cuestiones a la discusión pública, planteándolas de forma lo suficientemente abierta como para no prefigurar las respuestas y 2) sugerir algunas líneas de análisis y alternativas de respuesta desde mi particular punto de vista y desde la situación (España-Europa) en que la crisis se plantea.

No ignoro que hay otros contextos (asiáticos y latinoamericanos) donde la crisis - si se puede usar tal palabra- no es recesiva sino de crecimiento y que no tienen (al menos de momento) burbujas que desinflar. Pudiera ser entonces que, o bien las preguntas y eventuales respuestas no son concreta e inmediatamente relevantes para esos contextos, o lo son solo periféricamente. La cuestión es, sin embargo, que, en la medida en que las condiciones y procesos (económicos y políticos, pero también sociales y culturales: Ramoneda, 2012) que han creado la situación crítica, tengan lugar en las "economías emergentes" y en sus correspondientes sociedades, la posibilidad de estos cataclismos existirá; la amenaza es, en ese sentido, ubicua y potencialmente universal. Entiendo que la dimensión planetaria de varias de las fuerzas causantes del choque secular y su voracidad operativa aconseja tomar nota de lo sucedido... aunque, al parecer y según el axioma (tan nefasto para la prevención), en asuntos humanos "nadie escarmienta en cabeza ajena".

\section{Poder y empoderamiento: significado y temas básicos}

La pertinencia y oportunidad del empoderamiento es patente: no solo ha pasado a ser parte del vocabulario y la retórica social cotidiana de la educación, la acción social, la política o los negocios, lo que ha sido reconocido formalmente con la inclusión del término en el Diccionario Panhispánico de Dudas (2005) o el Clave de la editorial SM (2006). Ha irrumpido, también, en el pensamiento académico donde ha generado un vivo debate conceptual (iluminador a 
veces, mera cacofonía nominalista otras) y variados intentos de clarificación de la naturaleza, estructura y características operativas del concepto: Berger y Neuhaus (1977), Laue y Cormick (1978), Rappaport (1981, 1987), Zimmerman (2000), Kofkin (2003), Montero (2003, 2009), Musitu y Buelga (2004), Nelson y Prilleltensky (2005), Hombrados y Domínguez (2007), Sánchez Vidal (2007). No es mi intención resumir aquí ese abigarrado conjunto o pronunciarme sobre él, sino solo enunciar los "hechos básicos" del tema: aquellos datos y temas fundamentales del empoderamiento que uso como punto de partida para discutir, como pretendía, la vigencia teórica y la viabilidad operativa del concepto. En mi opinión y a día de hoy, el significado y trascendencia del empoderamiento (o de parientes terminológicos como fortalecimiento, potenciación, reempoderamiento, apoderamiento, etc.) se puede condensar en cuatro puntos referidos a: 1) su significado teórico e ideológico, 2) su dimensión práctica, 3) el nivel de análisis y operación y 4) su naturaleza subjetiva u objetiva.

1. Significado teórico e ideológico. Como se ha indicado el empoderamiento introduce una idea global, operativa y positiva (el poder) en un campo dominado por nociones psicológicas, individualistas y deficitarias: el potencial teórico para ordenar y aprehender los datos y hechos del campo psicosocial se ve así grandemente ampliado (a la par que, según se verá, las complicaciones asociadas). Estamos así afirmando que el poder no es, solo, un fenómeno social (Bierstedt, 1952/1969; Dye, 1995; Martín Baró, 1989) sino, también, un asunto, una variable nuclearmente psicológica (May, 1972; McClelland, 1975). Y, desde ese punto de vista, adquiere pleno sentido la propuesta de Prilleltensky $(2004,2008)$ de exigencia de validez psicopolítica en el campo psicosocial.

Pero el significado y alcance de la idea de empoderamiento son infinitamente más amplios si se la estira en la dirección ideológica y, siguiendo a May (1972) y a las persistentes intuiciones comunitarias, asumimos que -frente a la creencia generalizada de que es algo lejano que detentan los otros, los poderosos- el poder, como potencial a realizar en el ser personal y comunitario, reside en nosotros, en la gente común, y se puede hacer efectivo si, siendo consciente de ese potencial genérico, la gente -la comunidad-actúa eficazmente para hacerlo realidad. Esa es la clave, y la podemos resumir prosaicamente afirmando que el poder es, cuando menos, un medio esencial para el desarrollo humano. Ya se ve, entonces, que el empoderamiento no es solo un concepto operativo, sino también un valor básico (aunque, como medio, instrumental) del campo comunitario y, en consecuencia, la base de un cambio cultural potencialmente revolucionario al alcance de la psicología considerada (como ya señaló el psicólogo George Miller en 1969 y, más explícitamente, el filósofo Alasdair McIntyre en 1985) como ideología central del mundo moderno: la posibilidad de cambiar la concepción que los humanos tenemos de nosotros mismos (y de crear nuevos modos de actuar) elevándonos a la calidad de sujetos agentes de nuestros propios fines y proyectos humanos, en lugar de ser servidores, agentes de otros. Ese es, naturalmente, el significado ideológico del empoderamiento que, como se ha indicado, fundamenta en psicología la idea y práctica del desarrollo humano, y en el campo social la acción social y política desde abajo (movimientos sociales, tercer sector, etc.) como complemento de la acción formal, desde arriba.

2. La dimensión práctica de la propuesta ideológica es obvia y dual: si el poder (colectivamente adquirido pero con efectos en los miembros individuales del colectivo) es un medio para los fines de desarrollo humano y justicia social, icómo puede la gente adquirir ese poder que en potencia posee?, icómo puede el psicólogo ayudar a hacer efectivo el poder que las personas necesitan para satisfacer sus necesidades, hacer realidad su potencial humano y, conjunta o individualmente, gobernar sus vidas? De nada sirve introducir la intuición de que la gente tiene un potencial "endógeno" de poder para desarrollarse personalmente y alcanzar la igualdad social si no podemos sugerir procedimientos y estrategias eficaces para hacer realidad ese potencial. Es más, la frustración de las prácticas "empoderadoras" no solo envenenará de desengaño y fatalismo la vida de los que creyeran en la idea, sino que acabará desvaneciéndola como una ilusión sin mayor consecuencia real. Ese es, precisamente, el reto, y el riesgo, de la 
psicología comunitaria (PC), especialmente agudo en situaciones como la actual.

3. iEs realmente el poder un fenómeno psicológico (individual, relacional, microsocial) y por tanto asequible a la técnica y al trabajo microsocial de base o, por el contrario, es un fenómeno globalmente macrosocial que se concentra en manos de ciertas élites y que opera (y se distribuye) por medio de mecanismos y estructuras sociales (las instituciones y las leyes) fuera del alcance del trabajo psicológico individual o grupal?

Notemos, primero, que esas dos posibilidades no son genéricamente excluyentes, una no niega (excepto respecto de las estrategias más eficaces para gestionar el poder) a la otra y, segundo, ya se ha respondido implícitamente la pregunta en la asunción inicial: el poder es, también, un fenómeno psicológico. Pero, repito, esa es solo una asunción de partida novedosa e incitante que necesita exploración teórica y revalidación práctica para su elevación a verdad provisional; es, de otro modo, una cuestión conceptual y prácticamente abierta. En lo referente a la abordabilidad micro o macrosocial del empoderamiento se pueden detectar dos corrientes divergentes en el pensamiento social. Una, representada por Wright Mills, sostiene la visión estructural y la concentración elitista del poder; otra (representada por Foucault o Simmel) apuesta por la difusión del poder entre las personas y grupos sociales y en las interrelaciones de unas y de otros. Insistamos, sin embargo, en que esas líneas son complementarias (como visión dinámico-relacional y como cristalización estática o estructural) y, salvo en las formas y prioridades de la acción, combinables.

4. ¿El poder es, por naturaleza, subjetivo u objetivo? La respuesta, obvia, está implícita en lo ya escrito: el poder es a la vez subjetivo y objetivo, contiene aspectos y procesos de ambos tipos. Partamos de una percepción subjetiva (individual o colectiva) de poseer (o no) un cierto grado y tipo de poder que crea unas expectativas de resultados deseados al relacionarse y actuar en la realidad social. En la medida en que los resultados de la acción e interacción confirmen (o defrauden) esas expectativas estaremos adquiriendo un poder "real" visible (objetivado) en ciertas realizaciones perso- nales o logros sociales a la vez que ampliamos (o reducimos) nuestra conciencia subjetiva de poder. Y, por otro lado, la acumulación de esas secuencias en ciclos o espirales dinámicas que alcanzará en distintos momentos grados variables de solidificación estructural en el individuo o el grupo estable. No hay, pues, contradicción de principio entre la visión subjetiva y objetiva del poder, entre su estática y su dinámica sea a nivel individual, relacional o colectivo. Una y otra están conectadas por alguna forma de dialéctica o retroalimentación en que, importa resaltar, los medios técnicos y humanos del que actúa son fundamentales para transitar de la subjetividad a la realización objetiva.

Para la práctica psicosocial y comunitaria, la cuestión del empoderamiento remite, entonces, a las posibilidades reales de conectar los elementos descritos; la potente intuición ideológica y teórica (1) con la práctica cotidiana y real (2) en distintas comunidades y medios sociales; el nivel micro, psicológico y relacional (3) en que suele operar el psicólogo con el nivel macro-estructural de la institución y la norma social; y, en fin, las visiones subjetivas y dinámicas relacionales y participativas en que se acostumbra a mover la acción psicosocial, con las realizaciones prácticas eficaces en términos de las aspiraciones y/o necesidades globales de la comunidad (4), en gran medida condicionadas por un poder social global (incluido el financiero) que ha experimentado una enorme expansión y concentración. Para calibrar esas posibilidades conviene examinar algunas cuestiones relacionadas con ellas, a saber: la eficacia ideológica del concepto de empoderamiento en el mundo actual teniendo en cuenta las características (concentración, distancia, opacidad y lógica operativa) del poder social global y su divergencia con el modo de actuar psicosocial; los aportes operativos que la PC puede ofrecer, así como los medios intelectuales, técnicos, personales e institucionales con los que, como práctica social, podemos avalar los ambiciosos fines del empoderamiento; los ingredientes básicos (sentimiento de potencia, relación y comunicación, acción colectiva) del proceso empoderador y los eventuales equilibrios entre ellos. A ello se dedica el resto del artículo. 


\section{Eficacia explicativa y práctica de la idea de empoderamiento}

Las ideas de poder y empoderamiento tendrán distintos significados según el contexto social y comunitario. En mundos sociales preindustriales o dominados por carencias extremas y necesidades básicas, la idea de empoderamiento (o la de desarrollo humano) será literalmente impensable, mientras que la sensación de impotencia tendrá una sólida base experiencial. Otras sociedades parecen tableros de ajedrez en que unos pocos actores todopoderosos (señores de la guerra, grupos terroristas, guerrillas, narcotraficantes, fuerzas armadas, etc.) juegan una macabra partida por el poder donde los civiles, meros comparsas o rehenes, quedan anulados, casi imposibilitados para constituirse en sujetos agentes y potentes. En una autocracia política tendrá pleno sentido hablar de dominación u opresión como sometimiento físico o coercitivo (y no solo psicológico) a un dictador o minoría que acapara el poder e impide a la mayoría acceder a él $y$, por ende, desarrollarse plenamente como personas y comunidades.

Este análisis se centra en sociedades posindustriales económicamente ricas y técnicamente desarrolladas que, teniendo las necesidades básicas de la mayoría de la población cubiertas y sistemas más o menos generosos de protección social, han experimentado transformaciones sociales y culturales profundas como la urbanización o la ruptura de los sistemas familiares, religiosos y comunitarios de vinculación, y han entronizado formas de vida basadas en el individualismo, la racionalidad utilitaria, el interés egoísta, la organización y planificación social, la competitividad y la eficacia productiva. Esas sociedades han forjado un complejo entramado sociotécnico en que el poder no se ejerce de manera abierta y coercitiva, sino sutil, indirecta y ubicua condicionando casi cada aspecto de la vida personal y social. Es en ellas donde, al hilo de la crisis ya descrita, centro el análisis de la eficacia ideológica y práctica del empoderamiento, sin descartar, como he indicado, que varias de las tendencias que les son propias estén ya actuando o puedan hacerlo, por su carácter "sistémico", en el futuro en sociedades como las descritas o en aquellas con "economías emergentes".

Las dificultades de la teoría y la práctica del empoderamiento en el trabajo psicosocial (o comunitario) en estos contextos derivan de las divergencias ya apuntadas entre las características y lógicas operativas de la estrategia comunitaria micro de empoderamiento y las del poder macro social que, por un lado, parece cada vez más concentrado y opaco, siendo, por otro, distinto, distante y -en apariencia al menos-incomprensible no solo para la gente común (la comunidad), sino también para el practicante comunitario en cuyas funciones entraría, según muchos, ayudar a esa gente a entender lo que pasa y conectarlo con sus vivencias y luchas cotidianas.

\section{Centralización y concentración del poder}

En su brillante estudio de la "élite del poder" estadounidense, el sociólogo W. Mills (1957) señala cómo la centralización en instituciones que monopolizan el poder, militar y político primero, económico después -junto al "equilibrio" de los grupos intermedios y la fragmentación y desorganización de los antiguos "públicos" deliberantes y organizados (Dewey, 1927/2004; Habermas, 1962/1981)-genera, por un lado, una elite de poder (el "complejo militar-industrial") y, por otro, unas masas amorfas, impotentes y manipuladas. Aceptemos o no la polémica tesis de Mills (su contraria es la difusión "hacia abajo" y en las relaciones del poder), la tendencia a la concentración del poder parece una realidad innegable a medida que el poder corporativo se extiende en una sociedad. Baste añadir el aumento explosivo del poder que la moderna técnica industrial, comunicativo-informativa, organizativa y publicitaria (Noble, 1987; Sánchez Vidal, 2009) ha puesto en las sociedades posindustriales (Bell, 1976) en manos de ciertos grupos cada vez más mediatizados por los poderes financieros (petroleras, empresas telecom y puntocom, fondos de pensiones y grandes especuladores, bancos, aseguradoras, agencias de rating, etc.) y por una legislación (sociedad anónima, desregulación financiera e informativa...) que garantiza su libertad de acción con mínimos contro- 
les democráticos, para redondear un cuadro que el sociólogo Robert Lynd (1949) resume con elocuente simplicidad: "El problema a que nos enfrentamos hoy es que, en una época que vive cada vez más de la ciencia y la tecnología, el control empresarial de la ciencia y de su aplicación a las necesidades humanas da a la empresa privada el control efectivo de todas las instituciones de la democracia, incluido el propio Estado" (pp. 109-110).

La opacidad y anonimato de las personas y reglas que rigen estos conglomerados es otra característica importante de esos grupos cuyo lema habitual es pasar desapercibidos y cuyos nombres, significados y forma de reunirse y acordar cosas mutuamente beneficiosas ignoramos en su casi totalidad... hasta que una crisis económica nos hace conscientes de la increíble trama que la negligente conformidad y la inacción mayoritaria han permitido que ciertos grupos privados construyan, con la anuencia de nuestros representantes políticos y legislativos y con la activa legitimación intelectual de ciertos sectores de la alta y baja cultura.

La acción psicosocial o comunitaria, que busca el empoderamiento en un nivel micro aparece, en la práctica, patéticamente insuficiente para contrarrestar (por sí sola) estas tendencias macro del gran poder que condicionan seriamente tanto el punto de partida de la acción como la forma de realizarla y su eficacia final. "Remedios" comunitarios típicos son la información y la ayuda en la "toma de conciencia”, la organización social, la participación en la toma de decisiones formales y en la acción informal o el apoyo a asociaciones y movimientos sociales. Aun cuando esas estrategias vayan en la dirección correcta al buscar el empoderamiento desde abajo con base en la injusticia e indignación social y al número de perjudicados que se pueden movilizar para contrarrestar el dominio de grupos organizados o y que usan las regulaciones y leyes $-y$, sobre todo, de la falta de ellas- en su propio beneficio, la cuestión es la adecuación, suficiencia y viabilidad estratégica de esos métodos para lograr el empoderamiento o el cambio social estructural. ¿Cómo convencer, por ejemplo, a la gente de que se rebele y movilice contra el sistema cuando su puesto de trabajo está en peligro y a lo que realmente aspira es al bienestar y forma de vida que tenía antes de la crisis (no a cambiar "el sistema")? Si la PC aspira a un cambio con la gente, será inviable si la mayoría no quiere el cambio o no quiere el tipo de cambio que los psicólogos comunitarios propugnamos. $\mathrm{O}$, por otro lado, icómo ayudar a la información y "toma de conciencia" de la comunidad sobre lo que está sucediendo cuando la mayoría de nosotros no tiene el conocimiento o la comprensión mínimamente adecuada de fenómenos económicos y financieros tan complejos y opacos en que los propios economistas parecen confundidos y divididos?

\section{Lejanía e incomprensibilidad}

La estrategia comunitaria de trabajo se basa en la cercanía y en promover la interacción humana directa y la experiencia compartida para generar comunidad y dinamismo social. Esa es la lógica detrás de métodos como el trabajo en el territorio, el acercamiento de las instituciones (políticas, de control social, de servicios, etc.) a la comunidad local, la propuesta de espacios psicosociales de relación y participación o la promoción de redes de actores o grupos aislados. Esas son estrategias particularmente acertadas y valiosas en la doble dirección de generar comunidad (sentimiento de pertenencia) y, en el plano práctico, poder compartido. La cuestión es, de nuevo y dejando de lado el problema de la diversidad, como conectar esos dinamismos basados en la cercanía, la relación y la comunicación con un nivel macro social que opera con lógicas de lejanía (sus instituciones y hechos parecen lejanos e inalcanzables) y una complejidad real y opacidad deliberada que los hace casi incomprensibles (ergo inatacables) en el imaginario colectivo (y en el de muchos de los profesionales). El uso de estrategias sociales o mediáticas de visibilización tanto de los poderes opacos como de las víctimas puede tener cierta eficacia paliativa, aunque no está claro que basten para afectar, de entrada y por sí solas, a los mecanismos y fuerzas macro. El caso de las plataformas antideshaucio -que se oponen visiblemente en calle al deshaucio de familias concretas por parte de los bancos- sería, en esa línea, un ejemplo interesante. 
La visión de unas fuerzas anónimas, lejanas, opacas y en apariencia todopoderosas ("los mercados") que alienta el fatalismo y la pasividad, señalaría en principio la conveniencia de que el psicólogo de lo común asuma la función de "vanguardia ilustrada" que de alguna forma (y junto a otros actores sociales) facilite tanto la "toma de conciencia" de los problemas y del potencial de poder de la gente como la acción organizada consiguiente. Pero, debemos tener claro que asumir responsablemente esa función no es tarea fácil; exige, por el contrario, elaborar argumentos convincentes basados en el conocimiento de lo que sucede (no trillados lugares comunes), medios técnicos probadamente eficaces, valores éticos legítimos y relaciones basadas en la confianza personal y técnica. Creo que en esa cuádruple dirección el campo psicosocial tiene mucho camino por andar. La mera retórica voluntarista que no vaya acompañada de argumentos convincentes e informados, técnicas eficaces, valores legítimos y honestidad relacional difícilmente podrá "competir" tanto con las impresiones y arraigadas creencias que la gente alcanza por sí misma con base en los "hechos del poder" y a su propia percepción de esos "hechos" (el poder lo tienen los otros, no se puede hacer nada contra los poderosos, siempre habrá ricos y pobres, siempre pagan los mismos, etc.) como con las estrategias conservadoras de pasividad y miedo que en coherencia usa. Y es que, en fin, los argumentos y las técnicas psicosociales ni serán una alternativa convincente ni suficiente, sin el cambio de esos "hechos" en los niveles macroeconómico y político (regulando, por ejemplo, los mercados y los flujos financieros en beneficio de la sociedad) y de las relaciones socioeconómicas que los sostienen. Ese cambio estructural exige, parece evidente, una importante y sostenida presión de la sociedad en su conjunto. Y es ahí donde podemos encajar, en un cierto nivel, algunas de las estrategias psicosociales de "activación" y actuación.

\section{¿Puede la PC contribuir al empoderamiento social? Los retos prácticos}

Si la divergencia de lógicas del empoderamiento comunitario a nivel micro y el gran poder centra- lizado, distante, lejano y distinto (incomprensible) cuestionan la eficacia ideológica y práctica del empoderamiento, es inevitable preguntar en qué medida puede la $\mathrm{PC}$ contribuir al empoderamiento comunitario y personal en las actuales circunstancias críticas. Complemento aquí las consideraciones ya hechas, revisando, a partir de la evolución de la PC, los modelos de empoderamiento disponibles y su adecuación social así como algunas exigencias lógicas para mejorar la viabilidad práctica del empoderamiento comunitario desde la psicología.

Desde su tumultuoso nacimiento en los años 60 del pasado siglo, la PC "del Norte” (Sánchez Vidal, 2006, 2007) ha experimentado una serie de cambios relevantes. Primero, se ha institucionalizado académica y socialmente, consiguiendo unos medios y audiencia social con una virtualidad ambivalente: tener medios y poder facilita la expansión del discurso y la práctica de un campo pero conlleva también dependencias sociales, confrontación con instituciones con valores poco o nada comunitarios y el riesgo de autocomplacencia y una cierta "corrupción" inherente a la posesión de poder y reconocimiento social. Segundo, la actitud social ha cambiado sustancialmente: el clima de cambio y turbulenta ilusión de los 60 (cuando creíamos que todo era posible) ha devenido pasividad, complacencia con el bienestar material logrado y, ahora, miedo a perder ese bienestar y las conquistas sociales acompañantes. Esa pérdida de sintonía con el sentir social mayoritario está planteando (en el Norte y en el Sur) serias dudas "existenciales" al campo que, ante la dificultad de seguir sosteniendo el cambio con una gente -que o no quiere cambiar o busca cosas distintas a las que la PC puede ofrecerle-, no tiene claro hacia donde ir.

Tercero, la tecnificación, espoleada en buena parte por la institucionalización académica y social y la relativa popularidad de lo comunitario en el ámbito social: se ha multiplicado la demanda de técnicas, fórmulas, talleres y recetas para actuar, intervenir, planificar, investigar-actuar, evaluar, trabajar en red... o lo que sea. La técnica se justifica por la necesidad imperiosa del practicante de métodos y procedimientos eficaces en ausencia de los cuales la PC queda reducida a una retórica o un 
haz de buenas intenciones. El problema es que la excesiva insistencia en lo técnico (el know how) ha hecho olvidar las dimensiones políticas (y morales) de la práctica y los ideales de justicia y servicio que la inspiraron en sus inicios. (En el sur latinoamericano la situación parece casi opuesta: el énfasis en el "posicionamiento" político y el compromiso social ha oscurecido otras dimensiones -la técnica y la verificación empírica- del trabajo comunitario). La introducción de la idea de empoderamiento en la segunda parte de los 70 y el amargo despertar a la realidad del gran poder sin control del dinero -que la actual crisis se ha limitado a hacer visible: siempre estuvo ahí- han devuelto a su sitio la relevancia y necesidad del poder a la par que la enorme dificultad del empoderamiento psicosocial en tales circunstancias.

Pero, por otro lado, estamos en los albores de la exploración teórico-práctica del empoderamiento, de modo que apenas tenemos algunos esbozos para guiar la práctica. Uno está contenido en la revisión de Zimmerman (2000); otro, que uso aquí (Sánchez Vidal, 2007) propone tres modelos operativos de empoderamiento. El modelo cooperativo (ilustrado por Prilleltensky, 1997) asume que, siendo el poder un recurso ilimitado, se puede crear y compartir y por tanto se puede promover en relaciones cooperativas que mantienen la solidaridad y vinculación social. El modelo competitivo y de conflicto (por ejemplo, Laue \& Cormick, 1978) asume que el poder es un recurso escaso por lo que el empoderamiento de los más débiles exigirá redistribuir aquel o bien que esos se apoderen del poder de los que lo acaparan, que nunca lo van a ceder por las buenas. El modelo de recursos asume que el poder (y otros recursos) se crea al constituir un espacio social (grupo, institución, equipo, empresa, asamblea, asociación, etc.) con lo que aquel variaría (aunque no sea realmente ilimitado) en función del espacio social y de lo que aporten sus constituyentes (energía y deseos de trabajar, organización, conocimiento, interacción y relación, técnica, etc.), con lo que la clave de las posibilidades de empoderamiento y desarrollo humano serán la forma más o menos equitativa en que se distribuyan los recursos creados y la posibilidad de $-y$ disposición a- acceder a ese poder por parte de sus miembros. Aunque, en mi opinión, el tercer modelo es el que describe más fielmente la naturaleza y forma de operar del empoderamiento social-dibujando los otros dos condiciones sociales antagónicas que permitirían el uso eficaz de una (cooperativa) u otra (competitiva y de conflicto) estrategia operativa- las dificultades se hacen más evidentes cuando usamos para el análisis las estrategias centrales a los otros dos modelos.

$\mathrm{Y}$ es que, en efecto, al considerar la acción comunitaria en el contexto social (algo anómalamente ausente de tantas y tantas descripciones) vemos otra discordancia -una colisión, más bien- operativa (y asuntiva) entre la lógica comunitaria y la de las sociedades industriales, asociada al mencionado cambio en su clima social durante el medio siglo pasado. Mientras que la lógica comunitaria favorece (por muchas y buenas razones tanto de principio como de consecuencias) la estrategia cooperativa, "la sociedad" opera -y asume-cada vez más la lógica competitiva (eventualmente de conflicto), sobre todo en sus esferas técnico-productivas y económicas cada vez más centrales, no solo para la producción de bienes y servicios que son (en la percepción colectiva y en la realidad construida sobre supuestos materialistas) la base del bienestar social, sino para la formación de los valores y supuestos psicosociales que en buena parte forjan (a través de tantos y tan masivos mecanismos como los medios de masas) ideales y metas colectivas como el desarrollo humano y la forma de alcanzarlo.

¿Qué posibilidades tiene la PC operando en un nivel micro y con los medios que realmente posee de cambiar la lógica valorativa y productiva social macro que cuenta con tantos y tan poderosos medios en tanto no cambie el modelo, materialista y centrado en la abundancia y el exceso, de desarrolo humano actual? Esa es una pregunta clave que, aunque no podemos discutir aquí, debería abrir en la PC (en la acción psicosocial en su conjunto) un espacio de reflexión y debate sobre la relación entre desarrollo humano y el exceso, no el déficit y la necesidad -motores tradicionales de la acción psicológica y social-. La evidencia de que la abundancia material y el exceso de aportes psicológicos y sociales ha generado, no desarrollo, sino, a menudo, aliena- 
ción, deformaciones y nuevas patologías humanas (Fromm, 1941, 1955; Galbraith, 1984; Horney, 1937; Mills, 1951; Ortega y Gasset, 1930/2005) obliga a replantear el tema tanto en los contextos en crisis de crecimiento (y consumismo creciente) como en aquellos en recesión y austeridad obligada.

Retomando la línea expositiva del empoderamiento, considero ahora cuatro requisitos que la PC habría de cumplir para ser viable (y creíble).

1. Mostar que tiene los medios para realizar los ambiciosos fines de empoderamiento y cambio social propugnados; cuestión crucial que retomo en el apartado siguiente.

2. Reconocer que las comunidades no son islas flotando en el vacío social, sino que -junto a una multitud de agrupaciones- forman parte de un entramado social mayor del que son, a la vez y en procesos continuos, criaturas y creadoras. Por tanto, un cambio en las comunidades puede tener algún impacto social más amplio, pero, con certeza, un cambio social global (legislativo, económico, educativo, etc.) afectará seriamente las condiciones de vida las comunidades así como sus propios esfuerzos (y los de los agentes externos) por mejorarlas. En el tema que nos ocupa, y como se ha sugerido, un cambio en el reparto del poder global (reequilibrar el poder político y el económico, permitir la concentración o dispersar el poder empresarial, etc.) o en las "reglas del juego" (leyes, regulaciones, etc.) que ordenan las relaciones sociales de poder no solo tiene un impacto incalculable en la vida de la gente, sino que, a menudo, escapa tanto a la comprensión cabal de cómo afecta a las vidas de las personas como a las estrategias de empoderamiento o mejora-iniciadas por la comunidad o psicosocialmente inducidas desde fuera- en el nivel micro.

3. Reconocer que la acción psicosocial es, en realidad, solo una parte de los esfuerzos autoiniciados o externos para obtener el poder y los medios con que alcanzar los fines o las aspiraciones colectivas. En su libro Democracia y Educación (1915) John Dewey distingue entre la educación incidental que se adquiere informalmente en toda asociación humana y los esfuerzos deliberados que, como educación formal, realiza la sociedad para asegurar la renovación de la adaptación colectiva. Ampliando ese análisis a la mejora de la vida comunitaria identificaríamos tres tipos de esfuerzos: a) los de la propia comunidad (más deliberados que incidentales, en general) como grupo humano con cierta conciencia de sus problemas y aspiraciones y con algunos medios para abordarlos; b) los de las instituciones sociales (y ciertas agrupaciones complementarias) cuya misión es resolver tales problemas (vivienda, trabajo, seguridad, salud, etc.) en el conjunto de la sociedad o en la unidad administrativa (municipio, comarca, región...) de que es parte la comunidad y c) la acción social profesional (que puede o no ser parte de la acción institucional) y que puede actuar con base en una demanda comunitaria a un encargo institucional o por iniciativa propia.

Este esquema tripartito deja claro que la aportación de los psicólogos de lo social (deliberada y usando una técnica con fundamentos científicos, su aportación distintiva) es solo una parte de los esfuerzos totales de cambio con los que pueden (o no) estar integrados, resultando (o no) complementaria y sinérgica (o contraproducente) respecto de ellos. De ahí se deduce que el trabajo comunitario (en su doble nivel: PC, más personal, y desarrollo comunitario, más global pero no específicamente psicológico) para ser efectivos deberían, primero, reconocer el resto de esfuerzos, y, segundo, buscar la complementariedad o sinergia con ellos (salvo que existan razones políticas y morales de peso en contrario). Eso define una función bien aditiva (no necesariamente protagonista o principal) de la acción comunitaria respecto de los esfuerzos de la comunidad (y, eventualmente, institucionales), bien coordinadora de la acción de otras agencias o roles profesionales, bien, en fin, de colaboración con esos esfuerzos. Aunque entiendo que este tipo de trabajo se hace ocasionalmente, debería ser una práctica mucho más extendida.

4. Elaborar, como parte de la reflexión ya aludida, la propuesta de un concepto -contraculturalde desarrollo humano esencialmente desvinculado del exceso simbólico y el consumo material. Tal propuesta debería ir acompañada de una reconsideración de los sistemas psicológicos y sociales de control y modulación que hagan posible tanto la desvinculación del bienestar meramente material, como una no- 
ción de desarrollo humano que incluya, junto a las potencialidades y capacidades, los límites y costos del crecimiento personal en interacción con otros y con un mundo social culturalmente complejo y psicológicamente absorbente. El punto de partida ya existe: puede rastrearse en la literatura sobre salud mental positiva, psicología humanista (y su pálida reencarnación en "psicología positiva"), crítica de la sociedad de masas y psicoanálisis sociocultural.

\section{Medios y fines}

Si la PC (la acción psicosocial en general) quiere, por un lado, transitar desde la utopía o el rescoldo de un otrora vivaz movimiento social a una técnica social eficaz y complementar, por otro, la autojustificación con base en el compromiso social con la responsabilidad social, debe mostrar que, a falta de resultados empíricos convincentes (que difícilmente serán, en todo caso, resolutivos o decisorios), tiene los medios para lograr los fines, el empoderamiento en este caso. Esa cuestión, fundamental para cualquier práctica que se pretenda eficaz y responsable, reclama una reflexión permanente al hilo de la práctica y, en función de esa, un reajuste tanto del papel y el sentimiento de potencia del campo, como de las proclamas públicas que se hagan. Considero, como guía eventual de tal reflexión y autoexigencia, cuatro tipos de medios implicados en la práctica psicosocial: ideológicos, técnicos, personales y morales, e institucionales.

\section{Medios explicativos e ideológicos}

Permiten explicar los hechos sociales, comprender el poder como fenómeno multiforme y guiar la construcción teórica y la práctica psicosocial al servicio de ciertos valores morales, como el desarrollo humano y la justicia social. Ya se resaltó el potencial revolucionario que como ideología del humano y la acción social tiene el concepto. También, lo crucial del paso efectivo de la teoría a la práctica sin el cual el empoderamiento puede acabar reducido, como ha sucedido tantas veces, a chatarra ideológica, a una idea luminosa pero inviable cuya vigencia acaba cuando deja de estar de moda. No solo necesita el psicólogo, entonces, aprender más de la práctica y la investigación empírica sobre el empoderamiento y sus dinámicas teóricas y prácticas, objetivas y subjetivas, personales, relacionales y globales; debe también, si ha de ser "ilustrador" de la comunidad, o bien colaborar con otros especialistas o bien aprender más sobre el funcionamiento de los mercados y los poderosos mecanismos psicológicos entrelazados con los intereses económicos y las reglas sociales que facilitan el consumo desenfrenado, la especulación, o la formación de burbujas. Y, sobre esa base, ser capaz de criticar ciertos aspectos de la cultura actual -la codicia, la legitimación del egoísmo económico y el beneficio rápido, el individualismo "toxico" (Bellah, Madsen, Sullivan, Swidler \& Tipton, 1989) o la alegada contradicción de neoliberalismo y democracia- no solo por sus nefastos efectos sociales, sino, sobre todo, porque orienta a las personas hacia una forma de desarrollo globalmente inviable y a menudo humanamente alienante o destructiva. Siendo, también, conscientes de que ese rumbo nos adentra en el laberinto de las grandes opciones sociales y políticas en las que el aporte de la psicología y los psicólogos dista de ser claro.

\section{Medios técnicos}

Las herramientas, procedimientos y estrategias psicológicas que poseemos para alcanzar o facilitar el empoderamiento comunitario constituyen, ya se ha dicho, la esencia de cualquier práctica que se pretenda eficaz y legítima, y presentan, en el caso del empoderamiento, varias dificultades. Primera, la desproporción entre la gran retórica ideológica y las limitadas técnicas disponibles para hacerla realidad. Segunda, aunque se dispone de "técnicas" (equidad relacional, creación de ilusión, fomento de la conciencia de poder, estímulo del liderazgo, fomento de la interacción, organización social, mediación con instituciones, evaluación de necesidades y programas, promoción de habilidades sociales, etc.), esas ni son exclusivamente psicológicas ni tampoco exclusivamente técnicas, sino, además, personales y morales. No se trata de instrumentos externos, sino de que, por un lado, el propio psicólogo es, como ha repetido Carl Rogers, parte de la técnica y, por otro, 
nosotros mismos (además de personas) somos recursos o medios para la comunidad. Nada que objetar a la no exclusividad psicológica de los medios, pero quizá deberíamos excluir el sustantivo "psicología" o el calificativo "psicológico" al nombrar técnicas multidisciplinares de trabajo. La implicación personal como técnica, hace necesario, por otra parte, introducir el principio de autocuidado (Sánchez Vidal, 2004, 2007) para garantizar que los practicantes son reconocidos como personas -no solo como medios técnicos-y su integridad está asegurada. Y tercera, debemos probar empíricamente que estos medios son eficaces en términos de resultados y consecuencias y no solo de las intenciones o pretensiones subjetivas de los practicantes. Y, de nuevo, ahí puede haber una discrepancia no solo entre pretensiones subjetivas del practicante y consecuencias objetivas de su práctica, sino también entre el nivel micro de ciertas acciones (y del alcance de las técnicas usadas) y el nivel macro del empoderamiento -o el cambio-social que suele requerir $-y$ hacer uso deotros medios y estrategias (legislativas, políticas) que exceden con mucho lo psicosocial.

\section{Medios personales y morales}

La separación entre medios técnicos y personales en la acción psicológica o social es, a diferencia de otros campos, borrosa: el psicólogo (o la psicóloga) no solo usa medios externos (de base científica o no), sino que el mismo (ella misma) es, como persona, un medio que aporta ciertas capacidades personales (motivación y dinamismo, empatía, idealismo, intuición, capacidad de relación y comunicación, etc.) que, fertilizados por las técnicas estandarizadas, deben potenciar la eficacia de sus acciones e interacciones. Este tipo de medios es, sin duda, una de las grandes fortalezas del trabajo comunitario. Pero puede resultar su mayor debilidad si no va acompañado de los medios técnicos y cognoscitivos adecuados y proporcionados a las metas perseguidas como prueba la alta incidencia del estrés y el burnout que, como se ha dicho, aconsejan el autocuidado.

Los recursos o medios morales (Sánchez Vidal, $1999,2004,2007)$ son las convicciones y valores elaborados por el colectivo psicológico que, una vez explicitados y discutidos socialmente, guían la acción psicosocial ayudando a resolver los problemas y dilemas prácticos concretos. Enuncio telegráficamente algunas orientaciones y pautas útiles en ese terreno: el poder (y la técnica) son solo medios (valores instrumentales) para unos fines (propios y de la comunidad) por clarificar como valores finalistas; desarrollo humano, justicia social, poder compartido, reciprocidad y comunidad pueden ser valores sobre los que articular el trabajo empoderador; el empoderamiento es un medio que a nivel personal debe generar desarrollo humano (entendible como "la suma" de autonomía personal y vinculación social) y justicia social, aportando más poder a los que menos tienen. El psicólogo debe usar el poder técnico (o de otro tipo) que posee para el empoderamiento de los otros como personas y miembros de la comunidad, no el propio, pero tiene derecho a un autobeneficio legítimo (autocuidado) que lo reconozca, también, como persona; de poco sirven los valores e intenciones de partida si las consecuencias reales de las acciones emprendidas no son beneficiosas para la comunidad en los términos en que esa, no nosotros, defina; además de eficaz (basada en una técnica válida), la acción psicosocial debe ser respetuosa con los otros (reconociéndolos como fines y tratándolos sujetos dignos, capaces y agentes) promoviendo, según el caso, el diálogo y la comunicación horizontal o la redistribución vertical de poder.

\section{Medios institucionales y cambio social}

Parece claro que, si se ambiciona un verdadero cambio social (y cultural), hemos de contar con $-\mathrm{y}$ afectar a- las instituciones sociales, no solo a las personas y sus relaciones. En relación con el cambio social, las instituciones se pueden ver a la vez como un punto de partida (en cuanto son medios y aportan recursos para ese cambio) y punto de llegada, como consecuencia de un cambio que modifica los valores, medios o fines de la institución. En relación con la PC podemos identificar dos tipos de medios institucionales: los "propios" y los "ajenos", las instituciones sociales en general. Ya se indicó que el campo ha alcanzado un cierto grado 
de institucionalización, visible en las universidades, revistas científicas, congresos y las agrupaciones profesionales. El uso empoderador de esos medios institucionales propios presenta, al menos, dos problemas: 1) internamente su dinámica expansiva parece servir en realidad tanto al autointerés implícito (la consolidación del poder personal e institucional de los propios psicólogos) como a los intereses declarados de mejora y empoderamiento de la comunidad y 2) externamente el gremio comunitario suele mantener serias discrepancias valorativas y prácticas con las instituciones en que está "anidado" que dificultan tanto la misión nominal de trabajar para la comunidad como la posibilidad de "usar" esas instituciones (con una estructura de intereses y poder generalmente bien establecido) al servicio de aquella.

Esos (autointerés reproductivo y expansivo, divergencias de valores y lucha por el poder social) son, por otro lado, los mismos argumentos por los cuales las instituciones sociales "ajenas" (gobiernos, escuelas, centros de salud, medios de masas, etc.) son con frecuencia refractarias en la realidad (aunque nominalmente se muestren tolerantes y hasta favorables) al cambio social. Lo cual remite a temas ético-sociales familiares: el reconocimiento del autointerés legítimo y la pluralidad de actores y valores y, por tanto, la necesidad de diálogo y negociación, que debe ser precedida por una doble clarificación de los valores, propios - del psicólogo de lo comúny ajenos, los de la comunidad y las instituciones en que, y con que, aquel trabaja.

\section{La esencia del empoderamiento: la psicología en el laberinto político}

Cierro esta reflexión intentando desvelar, a partir de lo escrito, la esencia del empoderamiento psicosocial, sus ingredientes esenciales y sus interrelaciones. Creo que el empoderamiento se compone de tres ingredientes o procesos básicos: a) la creación del sentimiento personal y subjetivo de potencia; b) la relación y comunicación social para conocer los deseos compartidos y elaborar metas comunes y c) la acción colectiva eficaz en la consecución de tales metas y deseos. a) La creación o desarrollo de una conciencia o sentimiento subjetivo de poder potencial es -de forma similar a la autoestima en la acción individual- el punto de partida del empoderamiento y el umbral para el inicio de la interacción y acción que conduzcan al cambio social. Si personas y grupos no poseen un cierto nivel de conciencia -ligado a la experiencia previa- del poder que en potencia poseen, no se embarcarán en interacciones o acciones para conseguir metas porque no se ven capaces de actuar eficazmente y alcanzarlas. Aunque este sea, como se señaló, el ingrediente con mayor potencial trasformador (y el más fácil de modificar frente a la conducta real, según sabemos por la investigación en psicoterapia), encierra, por eso mismo, el mayor riesgo de frustrar las expectativas de empoderamiento y cambio. Debe ser, por tanto, manejado juiciosamente por los sujetos o practicantes: por una parte, la inacción fatalista de unos cederá la iniciativa a los poderosos (que sí suelen ser conscientes de su poder), fortaleciendo o polarizando el statu quo del poder, pero, por otra, la creación de una burbuja psicológica de poder irreal en relación con los medios y eventuales logros profundizará la frustración, la desconfianza en el practicante y la disminución tanto del poder real (para conseguir metas anheladas) como, en consecuencia, del sentimiento de potencia acumulado.

b) La relación y comunicación entre personas y grupos generará, por un lado y según la teoría comunitaria (Dewey, 1915/2009, 1927/2004; Kirpatrick, 1986; Sánchez Vidal, 2001, 2007), comunidad y conciencia de los deseos e intereses compartidos. Pero la realidad muestra que la interacción y la comunicación social no solo "producen" comunidad (o la ponen de manifiesto), sino también diferencias y conflictos por resolver o negociar, si se ha llevar a cabo una acción coherente, unitaria y eficaz (c). Por tanto, el trabajador psicosocial no solo debe facilitar la interacción social en condiciones que faciliten la emergencia de la comunidad y los intereses compartidos, sino además la definición de objetivos compartidos (ligada a la clarificación de valores y prioridades), la organización sostenida en torno a esos objetivos y valores mediante estrategias 
de movilización y acción eficaces y, en fin, la intermediación en la solución de conflictos. Casi nada...

c) Acción colectiva eficaz en la consecución de metas y aspiraciones conscientemente elaboradas y-en la medida de lo posible compartidas-por los participantes. Esta es la "prueba" final del empoderamiento sin la cual los pasos previos resultarán baldíos. Si la capacidad de "activación" y dinamización (y la organización para sostener la acción en el tiempo) es la esencia psicosocial de la fase anterior, la de esta es el conjunto de aportes técnicos (en forma de acción planificada, investigación-acción u otras estrategias) apropiados para alcanzar las metas formuladas que -además de ser realistas en relación a esos medios- incluirán, en el caso del empoderamiento, no solo fines externos y objetivos (como obtener ciertos recursos o aumentar la “densidad relacional”), sino también fines internos y subjetivos (como confirmar el sentimiento de potencia, mantener la cohesión o reestructurar el grupo). Dado que las comunidades no suelen tener poder económico, coercitivo, institucional o mediático, sino, en general, el "poder de los números", la acción conjunta (y organizada) parece esencial en este nivel micro, pues los poderosos acostumbran a estar bien organizados y suelen contar con el respaldo de unas instituciones -que en buena medida representan sus intereses y valores- y de ideologías sociales (Bierstedt, 1952/1969; Martín Baró, 1989) que, además de dar legitimidad a esos intereses y valores, constituyen en sí mismas una forma de ejercer el poder (Dye, 1995).

Todo lo cual replantea, con la debida crudeza, la complejidad del embrollo político (la cruz de la moneda cuya cara era el potencial revolucionario del empoderamiento) en que se adentra la psicología cuando ingresa en el laberinto del poder: la dificultad del cambio institucional y de conectar técnicas (y análisis) microsociales con el cambio social global que abarca múltiples actores y fuerzas con lógicas generalmente más amplias y a menudo divergentes de la comunitaria. Si la ampliación de la conciencia de poder (a) y el fomento de las interacciones, clarificación de objetivos y mediación en conflictos (b) se dan en niveles -y usan estrategias- micro o mesosociales relativamente cercanas (y familiares) al quehacer psicosocial, la acción colectiva (c) para el cambio macro social -la acción política- los desborda ampliamente dejando al descubierto las incertidumbres e insuficiencias de lo comunitario (lo psicosocial en general) en ese laberinto: la falta de una ideología global sobre como organizar mejor una sociedad; el logro real de ideales como la justicia social (y el reparto global del poder) o la democracia o la redefinición del progreso ante el dominio tecnocrático en la era "posindustrial"; el fomento de la participación política y la lucha contra la pasividad y desapego de las mayorías, conscientemente inducidos desde arriba (Wolin, 2008) y/o derivadas de un sentimiento de creciente impotencia frente al auténtico poder, el económico, y de fraude de la democracia; la rendición de la política al poder económico y financiero; la reconversión de la democracia en espectáculo de la mano de nos medios de masas que apenas enmascaran la manipulación. Tampoco se niegan, quede claro, ciertas posibilidades de aportación comunitaria o psicosocial a la política global; los enfoques y métodos participativas y las estrategias de acercamiento a la comunidad de los asuntos políticos pueden, por citar solo un par de puntos, ser útiles para repensar la acción política.

Un empoderamiento efectivo exige, retomando el tema de sus tres ingredientes básicos, un cierto equilibrio de los tres componentes: concienciador, interactivo-organizador y acción social. Ya se ha señalado que en un campo tan joven e idealista como la PC suele crearse un desequilibrio de a) respecto a b) y c) abusando de la concienciación en perjuicio relativo de las posibilidades de interacción (y las dificultades asociadas a la diversidad real) y los medios técnicos de la acción colectiva aceptables para los valores e intereses de la sociedad en su conjunto. Debemos, por otro lado, evitar el vicio simétrico: la falta de ambición del campo en cuanto a los objetivos y empresas (de empoderamiento u otras) propuestos, así como la posición "buenista" (las propuestas de Dewey, 1915/2009, 1927/2004, son un buen ejemplo), según la cual si la gente se junta e interactúa se crea comunidad y el germen de la acción colectiva (aunque el exceso de individualismo parece, en realidad, una amenaza potencialmente mayor al espíritu comunitario). Un tercer 
exceso (c), el activismo amenaza, en fin, el campo comunitario, en que es ubicuo: se busca actuar (en general en base a nuestra conciencia social y la magnitud de los problemas e injusticias presentes), aunque no hayamos elaborado los fundamentos cognitivos y morales de la acción ni poseamos los medios técnicos apropiados.

Este escrito no debe entenderse como una invitación a la renuncia y la inhibición, sino, solo una llamada a la cautela y la humildad (no a la impotencia) tanto de cara a nosotros mismos y a nuestra propia percepción de potencia profesional y personal como, sobre todo, al explicar al público lo que la PC puede realmente hacer (en el campo del empoderamiento, el desarrollo humano o cualquier otro) en función de los medios a su alcance y de la evidencia empírica progresivamente acumulada. Entiendo que en ningún caso debe la PC (o el campo psicosocial en general) renunciar a su propio poder genérico de largo alcance, al potencial de contribuir a promover el desarrollo humano y la justicia social en la comunidad, favoreciendo en la medida de sus posibilidades ideológicas, técnicas, personales y morales e institucionales el desarrollo del poder de la comunidad y sus miembros. La "solución" es, creo, por un reajuste dinámico del rol psicosocial en función de las realizaciones y fracasos del campo, de sus progresos y retrocesos y de lo que vayamos aprendiendo de la investigación teórica y de la acción, propia y ajena.

\section{Referencias}

Bell, D. (1976). El advenimiento de la sociedad posindustrial. Madrid: Alianza Universidad.

Bellah, R. N., Madsen, R., Sullivan, W. M., Swidler, A. \& Tipton, S. M. (1989). Hábitos del corazón. Madrid: Alianza Editorial.

Berger, P. \& Neuhaus, R. J. (1977). To empower people. Washington: American Enterprise Institute for Public Policy Research.

Bierstedt, R. (1969). An analyisis of social power. En L. A. Coser \& B. Rosenberg (Eds.), Sociological theory: A book of readings (3a. ed., pp. 154-166). New York: Macmillan. (Trabajo original publicado en 1952)

Clave. (2006). Diccionario de uso del español actual (8a. ed.). Madrid: SM.
Dewey, J. (2009). Democracy and education. Lexington, KY: Reada. (Trabajo original publicado en 1915)

Dewey, J. (2004). La opinión pública y sus problemas. Madrid: Morata. (Trabajo original publicado en 1927)

Dye, T. R. (1995). Power and society: An introduction to the social sciences (7a. ed.). Belmont, CA: Wadsworth.

Fromm, E. (1941). Escape from freedom. New York: Holt, Rinehart \& Winston.

Fromm, E. (1955). The sane society. New York: Fawcett.

Galbraith, K. (1984). La sociedad opulenta. Barcelona: Ariel.

Habermas, J. (1981). Historia y crítica de la opinión pública: la transformación estructural de la esfera pública. Barcelona: Gustavo Gili. (Trabajo original publicado en 1962)

Hombrados, M. I. \& Domínguez, J. M. (2007). La potenciación comunitaria (empowerment). En I. Maya, M. García Ramírez \& F. Santolaya (Comps.), Estrategias de intervención psicosocial (pp. 39-43). Madrid: Pirámide.

Horney, K. (1937). The neurotic personality of our time. New York: Norton.

Kirpatrick, F. G. (1986). Community: A trinity of models. Washington, DC: Georgetown University Press.

Kofkin, J. (2003). Community psychology. Guiding principles and orienting concepts. Upper Saddle River, NJ: Prentice Hall.

Laue, J. H. \& Cormick, G. W. (1978). The ethics of intervention in community disputes. En G. Bermant, H. C. Kelman \& D. P. Warwick (Eds.), The ethics of social intervention (pp. 205-232). NewYork: Wiley.

Lasch, C. (1999). La cultura del narcisismo. Barcelona: Andrés Bello. (Trabajo original publicado en 1979)

Leahey, T. (2005). Historia de la psicología (6a. ed.). Madrid: Pearson Educación.

Lynd, R. (1949). "You can't skin a live tiger...". American Scholar, 17,109-110.

Martín Baró, I. (1989). Sistema, grupo y poder: psicología social desde Centroamérica II. San Salvador: UCA Editores.

May, R. (1972). Power and innocence. A search for the sources of violence. New York: Norton \& Co.

McClelland, D. (1975). Power: The inner experience. New York: Irvington.

McIntyre, A. (1985). How psychology makes itself true or false. En S. Koch \& D. E. Leary (Eds.), A century 
of psychology as science (pp. 897-903). New York: McGraw-Hill.

Miller, G. A. (1969). Psychology as a means of promoting human welfare. American Psychologist, 24(12), 1063-1075.

Mills, C. W. (1957). La élite del poder (2 ${ }^{\underline{a}}$ ed.). México: Fondo de Cultura Económica.

Mills, C. W. (1951). White collar. The American middle class. New York: Galaxy Books.

Montero, M. (2003). Teoría y práctica de la psicología comunitaria. La tensión entre comunidad y sociedad. Buenos Aires: Paidós.

Montero, M. (2009). El fortalecimiento en la comunidad, sus dificultades y alcances. Universitas Psicológica, 8(3), 615-626.

Musitu, G. \& Buelga, S. (2004). Desarrollo comunitario y potenciación (empowerment). En G. Musitu, J. Herrero, L. Cantera \& M. Montenegro (Eds.), Introducción a la psicología comunitaria (pp. 167193). Barcelona: Universitat Oberta de Catalunya.

Nelson, G. \& Prilleltensky, I. (Eds.). (2005). Community psychology. In pursuit of liberation and well-being. New York: Palgrave Macmillan.

Noble, D. (1987). El diseño de Estados Unidos. Madrid: Ministerio de Trabajo y Asuntos Sociales.

Ortega y Gasset, J. (2005). La rebelión de las masas. Madrid: Austral. (Trabajo original publicado en 1930)

Prilleltensky, I. (1997). Values, assumptions, and practices: Assessing the moral implications of psychological discourse and action. American Psychologist, 52(5), 517-535.

Prilleltensky, I. (2004). Validez psicopolítica: el próximo reto para la psicología comunitaria [Prólogo]. En M. Montero (Ed.), Introducción a la psicología comunitaria (pp. 13-40). Buenos Aires: Paidós.

Prilleltensky, I. (2008). The role of power, wellness, oppression, and liberation: The promise of psychopolitical validity. Journal of Community Pychology, 36(2), 116-136.

Ramoneda, J. (2012, junio). Una cultura de la incertidumbre y el miedo. Conferencia Inaugural de la IV Conferencia Internacional de Psicología Comunitaria, Barcelona, España.

Rappaport, J. (1981). In praise of paradox: A social policy of empowerment over prevention. American Journal of Community Psychology, 9(1), 1-25.
Rappaport, J. (1987). Terms of empowerment/exemplars of prevention: Toward a theory of community psychology. American Journal of Community Psycholgoy, 15(2), 121-148.

Solomon, B. (1976). Black empowerment: Social work in oppressed communities. New York: Columbia University Press.

Sánchez Vidal, A. (1999). Ética de la intervención social. Barcelona: Paidós.

Sánchez Vidal, A. (2001). Medida y estructura interna del sentimiento de comunidad: un estudio empírico. Revista de Psicología Social, 16(2), 157-175.

Sánchez Vidal, A. (2004). Acción social en tiempos de conformismo: por una ética posible de la intervención comunitaria. En A. Sánchez Vidal, A. Zambrano \& M. Palacín (Comps.), Psicología comunitaria europea: comunidad, poder, ética y valores (pp. 93-106). Barcelona: Publicacions de la Universitat de Barcelona.

Sánchez Vidal, A. (2006). Psicología comunitaria del norte y del sur. Lusíada, 3,189-205.

Sánchez Vidal, A. (2007). Manual de psicología comunitaria. Madrid: Pirámide.

Sánchez Vidal, A. (2009). De la servidumbre mecánica a la dominación blanda. Sueños y pesadillas técnicas. Documento no publicado.

Simmel, G. (1977). Sociología. Estudios sobre las formas de socialización (Vol. 1). Madrid: Alianza.

Solomon, B. (1976). Black empowerment: Social work in oppressed communities. New York: Columbia University Press.

Vallés, J. M. (2010, junio 11). ¿Cuánto mercado puede tolerar la democracia? El País. Disponible en http://elpais.com/diario/2010/06/11/opinion/1276207205_850215.html

Watson, P. (2002). Historia intelectual del siglo XX. Barcelona: Crítica.

Wolin, S. (2008). Democracia S. A. La democracia dirigida y el fantasma del totalitarismo invertido. Barcelona: Katz.

Zimmerman, M. A. (2000). Empowerment theory. En J. Rappaport \& E. Seidman (Eds.), Handbook of community psychology (pp. 43-63). New York: Kluwer Academic/Plenum Publishers. 